\title{
The Effect of Task Instructions on Students' Use of Repetition in Argumentative Discourse
}

\author{
Sandra Gilabert ${ }^{\mathrm{a} *}$, Merce Garcia-Mila ${ }^{\mathrm{a}}$ and Mark K. Felton ${ }^{\mathrm{b}}$ \\ ${ }^{a}$ Developmental and Educational Psychology, University of Barcelona, Campus Mundet, \\ P. Vall d'Hebron, 171, Barcelona, 08035, Spain; ${ }^{b}$ Department of Secondary Education, \\ San fosé State University, San fosé, CA, USA
}

The reasoning belief of argumentum ad nauseam assumes that when someone repeats something often enough, he or she becomes more convincing. The present paper analyses the use of this strategy by seventh-grade students in an argumentation task. Sixty-five students (mean age: 12.2, $\mathrm{SD}=0.4)$ from a public school in a mid-sized urban environment took part in the study. The students were asked to either argue to convince an opposing partner or argue to reach consensus with an opposing partner on three dilemmas that dealt with energy sources. Data were gathered according to a between-groups design that included one independent variable (argumentative goal: to convince $v s$. to reach consensus) and one dependent variable (the degree of argumentative repetitions). We predicted that in the condition to convince their partner, the students would use the repetition strategy more often in their attempts to be persuasive. Our findings show that the mean number of argumentative repetitions was significantly higher for the persuasion group for both of the most frequent argumentative structures (claim and claim data). The mean percentage of repeated claims for the persuasion condition was 86.2 vs. 69.0 for the consensus condition. For the claim data, the mean percentage for the persuasion group was 35.2 vs. 24.3 for the consensus group. Also, students in the persuasion group tended to repeat one idea many times rather than repeating many ideas a few times within the same argumentative structure. The results of our study support the hypothesis that the goal of the argumentative task mediates argumentative discourse and, more concretely, the rate of repetitions and the conceptual diversity of the statements. These differences in rates of repetition and conceptual diversity are related to the amount of learning produced by the instructional goal. We apply Mercer's idea that not all classroom argumentation tasks promote learning equally.

Keywords: Argumentation; Discourse; Learning

*Corresponding author. Developmental and Educational Psychology, University of Barcelona
Campus Mundet, P. Vall d'Hebron, 171, Barcelona 08035, Spain. Email: sandra.gilabert@ub.edu 


\section{Introduction}

Over the past 20 years, science education research has witnessed an increased interest in argumentation as an instructional approach and educational goal (Bricker \& Bell, 2008; Driver, Newton, \& Osborne, 2000; Duschl, 2008; Duschl \& Osborne, 2002; Jimenez-Aleixandre \& Erduran, 2008; Kelly \& Takao, 2002; Kuhn, 2010; Lehrer, Schauble, \& Petrosino, 2001; Maloney \& Simon, 2006; Mercer, Dawes, \& Wegerif, 2004; Nussbaum, 2011; Simon, Erduran, \& Osborne, 2006; Zohar \& Nemet, 2002). This interest has sprung in part from the widespread view that science is not the unequivocal and uncontested body of knowledge generated by a direct reading of nature that positivists once claimed. Instead, science is seen as a social construction that results from a process of inquiry within the scientific community, where public and private discourses are used to address controversies and move towards consensus. According to this view, to learn science is not to know what the last generation of scientists thought of the world, but to see how each new generation of scientists reelaborates our view of the world (Lemke, 2002). Duschl (2008) has proposed that this new view has led to a corresponding shift in science education from focusing on what we know in science to how we know what we know and why we believe it (p. 269). As a result, the National Research Council Report (Duschl, Schweingruber, \& Shouse, 2007) has established four goals for becoming proficient in science: (1) knowing the scientific explanations of the natural world; (2) generating and evaluating scientific evidence and explanations; (3) understanding the epistemic nature of scientific knowledge and (4) participating in scientific practices and engaging in scientific discourse. Together, these goals suggest that argumentation, the process of evidencebased reasoning, is central to students' conceptual understanding in the science classroom, and that argumentative dialogue can be used as a context for supporting and developing scientific reasoning (Chin \& Osborne, 2010; Driver et al., 2000; Kim \& Song, 2006; Syh-Jong, 2007).

According to the view that knowledge exists as a social entity rather than an individual entity, Vygotsky (1978) claims that knowledge construction is clearly scaffolded by classroom discourse and, within it, by argumentative dialogue. Based on this view, researchers have begun to investigate the role of argumentative discourse in science learning, with a growing body of research that reports on its positive effects (Kelly \& Chen, 1999; Kelly \& Crawford, 1997; Nussbaum, 2008; Zohar \& Nemet, 2002). These findings support the theory that argumentative discourse supports science learning by providing a context for the dialectical process of elaborating and juxtaposing rival hypotheses on a foundation of evidence, and drawing conclusions within a framework of alternatives. Argumentation has become a central element for science education as a heuristic to engage learners in the coordination of conceptual and epistemic goals (Kuhn, 2010), and also as a way to make student scientific thinking and reasoning visible (Osborne, Erduran, \& Simon, 2004).

However, there are factors that may limit the potential benefits of argumentative discourse for science learning. First, the participants in a dialogue may not have a clear understanding of argumentation. Osborne and Patterson (2011) point out 
there is an important distinction between scientific explanation, which presents and clarifies a consensually accepted view, and scientific argument which advances a contested view by advancing claims and evidence against alternatives. The problem is that science students often muddle these two discursive acts, producing explanations in lieu of arguments. As a result, while they may provide evidence in support of a claim in order to elucidate an idea, they do not necessarily demonstrate that their claim is more convincing than its alternatives. Similarly, Berland and Reiser (2009) argue that scientific explanation and argumentation are complementary practices, with the latter playing an essential role in using science to select the most robust explanations for phenomena or solutions to problems. Osborne and Patterson point out that while explanation may give students the opportunity to construct knowledge, 'only the practice of argumentation enables students to engage in the critical evaluation of claims to knowledge' (2011, p. 637). To truly reap the potential benefits of argumentative discourse for science learning, interventions must address this confusion by clarifying discourse goals for students before they begin arguing.

However, explicitly prompting students to argue may not be enough because not all kinds of argumentative discourses will lead to science learning. Argumentation is a broad category that can take many forms in natural conversation, including competitive exchanges where an individual's goals may be at odds with the process of reasoned discourse. Ideally, argumentative discourse promotes the critical evaluation of claims by creating a context for individuals to consider competing claims and evidence. However, argumentative discourse can also cause individuals to 'dig their heels in' and become resistant to alternative views. One way to examine the conditions that either support or impede effective argumentative discourse is to consider a speaker's discourse goals while arguing (Kroll, 2005; Makau \& Marty, 2001; Walton, 1992). Walton (1992) distinguishes the goals of persuasive dialogue from deliberative dialogue in argumentative discourse. In a persuasive dialogue, the goal of each speaker is to defend a viewpoint and undermine alternatives in order to convince an opponent to switch sides. Here, the goal is to win. Makau and Marty (2001, p. 84) suggest that when we argue to convince, we tend 'to approach disagreements as a winner-takeall fight [which] clearly obstructs our ability to understand one another or to solve our problems' and identify repetition as one of the strategies that negatively affects the quality of argumentation. Nussbaum and Kardash (2005) found that the goal to persuade in a writing task resulted in texts that were less likely to explore the opposing sides of an issue, demonstrating a kind of my-side bias. They caution that persuasive goals may be incompatible with counterargument because writers feel that entertaining opposing views makes their argument less convincing.

In contrast to persuasive dialogue where the goal is to convince, Walton (1992) proposes that in deliberative dialogue, the goal of both speakers is to arrive at a shared viewpoint by evaluating alternatives. In other words, the goal is to seek consensus. In a prior study (Felton, Garcia-Mila, \& Gilabert, 2009), we investigated whether these two different goal conditions (persuasion $v$ s. consensus) have a positive effect on learning about sources of energy measured by a pre-post test comparison, and found that although all groups of students in the study (including a no-dialogue 
control group) showed significant learning, the students in the consensus condition had the highest rate of content learning, followed by the persuasion condition and the control, respectively. In the present study, we return to these data to better understand the differences in science learning in terms of the discourse that transpired in each goal condition, specifically with respect to the use of argument repetition.

Sometimes speakers may engage in an informal fallacy known as argument ad nauseam, or proof by repeated assertion. This fallacy occurs when a speaker repeats an assertion in the face of contradiction, rather than strengthening the assertion through a process of substantiation and rebuttal. It represents a fallacy of informal reasoning because the speaker assumes that the simple repetition of an idea strengthens it. Johnstone's work (1996) in the field of conversation analysis notes that repetition is often used to create rhetorical presence, as a linguistic foregrounding of an idea, which can make it persuasive even without logical support, leading to a reasoning flaw.

Of course, in some cases repetition may not be a fallacy at all, but a simple expression of disagreement, when two speakers have reached an impasse and are unwilling to accommodate their opponents' views. In this case, speakers may repeat themselves instead of responding to questions or counter arguments in an effort to 'shout down' an opponent (Goodwin \& Goodwin, 1987). Scott (2002) proposes that repetition generally serves one of three primary purposes in a disagreement: '(1) to emphasize ... a point, (2) to refocus the talk on something the speaker wants topicalized, and/or (3) to attempt to gain the floor or have one's voice heard because of overlapping speech' (p. 316). She has found that as arguments become more hostile, repetition generally increases and changes in use from the first and second purposes to primarily the third.

Finally, repetition may be used as a persuasive technique, as is commonly found in the fields of advertising and politics. Johnstone (1987) points out that 'repetitions make things believable by forcing them into the affective field of the hearer and keeping them there' (p. 208). Cacioppo and Petty (1989) have shown that the strategy of repetition can have a positive effect on peoples' attitudes. They show that moderate repetition of the same communication seems to generate understanding of the message argued and a better attitude towards the message. This finding was confirmed by Claypool, Mackie, Garcia-Marques, McIntosh, and Udall (2004), when the condition was manipulated to make a message highly relevant but not when the message was less relevant. Thus, argument repetition can represent a goal-directed behaviour in persuasive dialogues used to strengthen the power or appeal of an idea, rather than add to its argumentative strength. Walton (1992) takes the modern view among argumentation theorists that fallacies can only be understood in relation to the context in which they appear. Thus, repetition may be a reasonable device for the purposes of propaganda (Walton, 1997), where the goal is to persuade, but may be inappropriate in a deliberation, where the goal is to examine alternative proposals in a reason-based dialogue (Walton, 1992).

Regardless of whether repetition represents a reasoning flaw, a simple expression of disagreement, or a persuasive technique, it can be considered antithetical to science 
learning when it moves discourse away from the process of elaborating and comparing competing points of view. In the extreme, repetition can inhibit learning by restricting the breadth of ideas and evidence explored in a dialogue, leaving participants with an impoverished understanding of opposing views. Thus, understanding what triggers this negative form of discourse is critical for optimizing the use of argument in the science classroom. Our main assumption is that students' goals during discourse are a mediating factor in their argumentative discourse and, ultimately, in their learning.

There are few studies that experimentally explore the goal conditions that elicit argument repetition in dialogues. In a case study on peer argumentation in a science summer camp, Kim and Song (2006) analysed the strategies used by eighth-grade students in an inquiry task (to find the conditions that create longlasting bubbles) designed to promote argumentation. Specifically, the authors focused on social strategies, which they categorized as conflictive or cooperative. The authors found that the conflict-inducing strategy accompanied a higher rate of repetitions in peer argumentation. This relation established by Kim and Song between repetition and conflict-inducing strategy is particularly interesting for our study, although (as mentioned) their meaning of repetition is slightly different from ours in the sense that it is not one's own repetition but the individual repeating what the partner just said:, 'you said that ... but ...' (p. 223), and may have a different dialogical function. In Kim and Song's sense, the repetition might serve to reframe a partner's statement to serve the speaker's argument, while in our work, we hypothesize that the function of repeating oneself is to become persuasive. In a study on the argumentative discourse of university students, Metsämäki (2009) also found that students used repetition of their own claims when they had to be convincing in a debate setting, but did not look at changes in frequency in other discourse settings.

Taken together, these previous studies suggest that persuasive task goals may elicit repetition more often in argumentative discourse than consensus task goals, but this relationship has not been tested experimentally and its implications for science learning have not been explored. The goal of the present paper is to analyse the use of argument repetition in reasoning by middle school science students in a socio-scientific argumentation task on the topic of renewable energy sources. We define argument repetition here as a speech act in which an argumentative structure and its content are reiterated or reasserted by the speaker without elaboration. Moreover, we operationalize argumentum ad nauseam as high repetition of the same argument structure and content (i.e. $\mathrm{CO}_{2}$ increase or production of radioactive waste) to distinguish it from other rhetorical uses of repetition where a wider array of structures and content may be repeated less frequently. More concretely, a structure is defined as the cluster of at least two elements from Toulmin's model of argumentation (claim, data, warrants, backing and rebuttal). Thus, when a student claims that nuclear power stations are bad because there may be leaks and it may be very dangerous when there are leaks, and then, later on, she says say: Well, I think $A$ (thermal power) is better because leaks are likely to happen and when there is one, it is very bad. Though the exact wording changes, we can see that the second utterance reiterates the same 
idea using the same claim and data as the first utterance. In such instances, we label the second utterance a repetition of the speaker's own first utterance.

Thus, our goal will be pursued by addressing three questions:

(a) Is the rate of repetitions of the same argumentative structure containing the same idea higher in the persuasive group?

(b) Within similar rate of repetitions, do the students in the persuasion group tend to repeat one idea many times rather than repeating many ideas a few times within the same argumentative structure?

(c) Do our results help explain prior data that showed that the students in the consensus condition showed a higher rate of learning? (Felton et al., 2009).

We predict that argument repetition is more likely to occur when a speaker has been instructed to convince a disagreeing partner (persuasive task) than when a speaker is instructed to reach agreement with a disagreeing partner (consensus task). Specifically, we anticipate that persuasive task goals will elicit more repetitions and fewer ideas than consensus task goals, as peers try to gain the upper hand in a competitive exchange. Consequently, we expect that the confirmation of this hypothesis will help explain the higher learning observed in the consensus-seeking group compared to the persuasive one (Felton et al., 2009).

\section{Method}

\section{Participants}

Sixty-five seventh-grade students (mean age: $12.2, \mathrm{SD}=0.4$ ) from a public school in a mid-sized urban environment took part in the study. ${ }^{1}$ The targeted age group was chosen according to developmental studies that show that preadolescents spontaneously begin to use arguments, counterarguments and rebuttals and to show a certain involvement with socio-scientific issues (Felton, 2004; Felton \& Kuhn, 2001; Golder, 1996). The participants were organized into dyads and were randomly assigned to the two conditions defined by the independent variable. In contrast with most argumentation studies, which ask the students to defend a position by roleplaying, we matched the students in each dyad according to their real opinions to preserve the authenticity of dialogues in the two task conditions. No specific training regarding good argumentation or regarding the use of repetition was provided to the students. They naturally navigated towards using what they thought would best work for them. The study was contextualized in the science classroom, thus no specific information about the objective of the study was provided to the students.

\section{Design}

Data were gathered according to a between-groups design that included one independent variable (an argumentative goal with two conditions, consensus vs. persuasion) and one dependent variable (the degree of argumentative repetitions). 
Independent variable. The independent variable consisted of the argumentative prompt that was provided to the dyad before each argumentation session on the given dilemma. The consensus group was prompted to reach consensus, and the persuasion group was prompted to convince their partners (see section Procedure).

Dependent variable. The dependent variable measures the amount of argumentative repetitions in each partner's discourse. This variable was operationalized in terms of two parameters. The first parameter was the percentage of repeated argumentative structures (see section Instruments) which was calculated by dividing the total number of repetitions of a given structure with identical content by the total number of occurrences of structures of that particular type and then multiplying by 100 to work with percentages. For example, whenever any claim data structure was repeated in a dialogue it was tallied, and the total number of claim data repetitions was then divided by the total number claim data structures produced by that student. The second parameter measured the percentage of unique ideas for each argument structure that students produced. It was calculated by dividing the number of unique ideas for a given argumentative structure by the total number of instances of that structure and multiplying by 100. This parameter complements the previous measure of the rate of repetitions by capturing the semantic richness of the dialogue. By measuring the number of unique ideas a student has produced, we can get a sense of whether they were repeating the same idea many times or a many ideas a few times. We worked from the assumption that a low density of ideas across repetitions (i.e. repeating oneself over and over) was indicative of more hostile, and less fruitful discourse.

\section{Procedure}

The experimental intervention was held in a science classroom and consisted of eight 50-min sessions. In the first two sessions, the students were presented with the content of a teaching unit about climate change and energy sources, and they were given a pretest. In sessions 3, 5 and 7, the students were presented with three different dilemmas regarding possible energy plans. For each dilemma, the students were asked to write a short essay to justify their position in the debate. In sessions 4, 6 and 8, the students were grouped into dyads and asked to argue on the topic of the dilemma for $15 \mathrm{~min}$. The two experimental groups were asked to argue according to their experimental condition (persuasion goal vs. consensus goal). The common instruction for both groups was as follows: 'Your task is to discuss the dilemma just presented to you with your partner for 15 minutes'. In the persuasive condition, the prompt continued 'The goal of the task is to convince your partner of the choice you have made about the dilemma by means of a good justification'. The prompt for the students in the consensus condition said 'The goal of the task is to reach an agreement with your partner and propose a consensus solution to the problem'. Finally, after session 8, the students took a post-test (identical to the pretest) to analyse their progress in learning the content. 


\section{Instruments}

To code the argumentative structures, we adapted Erduran, Simon and Osborne's rubrics (2004) based on Toulmin's model. The rubrics categorize each argumentative utterance in terms of the following argumentative elements: claim, data, warrant, backing and rebuttal. The combination of these elements resulted in 11 argumentative structures (see Appendix).

To calculate coding reliability, $45 \%$ of the dialogues were double-coded for the argumentative structures reaching $85.2 \%$ agreement. Repetitions were defined as any identical structure formed by the same elements and the same ideas, and 35\% of the dialogues were double-coded for repetitions. First, the identical structures were marked and, subsequently, those that were conceptually equivalent were also marked. For example, if a student justified a claim of nuclear energy by mentioning the reduction of $\mathrm{CO}_{2}$ several times using different words, each recurrence was coded as a repetition. The dialogue excerpt below illustrates repetitions made by Luisa, a student who argued against wind energy in favour of nuclear energy (see italicised fragments). ${ }^{2}$ The reliability of the coding of repetitions was $90 \%$. All discrepancies were resolved by discussion.

\footnotetext{
Dianne: Because it does not produce $\mathrm{CO}_{2}$ [windmill farms] and this would help reduce the greenhouse effect

Luisa: I am against the windmill farm because it will cause the birds' extinction, and it will have a negative impact on the landscape

Dianne: I think that the most important thing now is to stop climate change and its effects. If we do not defend the installation of these windmill farms, it will take years to have non-contaminating energy.

Luisa: But it will affect the birds, some birds will go extinct with an important negative visual impact in the landscape

Dianne: But $\mathrm{CO}_{2}$ also affects birds and the ecosystem

Luisa: But nuclear power stations do not produce any $\mathrm{CO}_{2}$
}

\section{Results}

We begin the Results section with an overview of the types of structures generated in the students' dialogues. Table 1 shows the total distribution of the types of argumentative structures.

As seen in Table 1, the mean number of total utterances coded as argumentative structures was $69.50(\mathrm{SD}=23)$. Only $84.6 \%$ of the utterances were coded. The remaining were utterances of the type 'you're just not thinking' or 'your choice is pitiful, you should think about what you are saying'. Such utterances were used to attack the partner in a way that was unrelated to the content. Thus, their coding was not relevant to the present analysis. Among the coded utterances, there were two argumentative structures that were used more frequently than the others (representing more than $75 \%$ of the total utterances). These two structures were claims $($ mean $=18.40, \mathrm{SD}=10.6)$ and claim data $($ mean $=25.6, \mathrm{SD}=10.5)$. The other structures were used less often and, consequently, their repetition was less relevant. 
Table 1. Means and standard deviations of the total number of structures according to type

\begin{tabular}{lrc}
\hline & Mean & Standard deviation \\
\hline Claim & 18.40 & 10.6 \\
Claim data & 25.60 & 10.5 \\
Claim backing & 0.50 & 1.0 \\
Claim rebuttal & 1.10 & 1.5 \\
Claim data warrant & 8.30 & 4.6 \\
Claim data backing & 0.50 & 0.8 \\
Claim data rebuttal & 1.70 & 1.3 \\
Claim data warrant backing & 0.40 & 0.6 \\
Claim data warrant rebuttal & 1.10 & 1.3 \\
Claim data backing rebuttal & 0.03 & 0.2 \\
Claim data warrant backing rebuttal & 0.07 & 0.2 \\
Total & 69.50 & 23.1 \\
\% Codified & 84.60 & 8.4 \\
\hline
\end{tabular}

Therefore, for the analysis of the dependent variable (rate of repetitions), we only looked at two argumentative structures: claim and claim data. As mentioned in the Methods section, the dependent variable was operationalized in terms of two parameters. The first parameter was the percentage of repeated argumentative structures, and the second parameter was the percentage of different ideas that appeared within each type of structure. The two parameters were compared across both conditions to test the hypothesis that a higher rate of repetitions took place in the persuasion condition.

\section{Rate of Repetitions: Repeated Argumentative Structures}

As seen in Table 2, the mean percentage of repeated claims for the persuasion condition was $86.2(\mathrm{SD}=13.4)$, whereas for the consensus condition it was 69 $(\mathrm{SD}=19.2)$. A Students' $t$-test used to compare the means (non-homogenous variances) showed that the persuasion group made significantly more claim repetitions than the consensus group $[t(59.02)=4.2 ; p=0.001$, effect size Cohen's $d=$

Table 2. Means (and standard deviations) for percentages of repeated argumentative structures, different ideas in the dialogs and effect size comparisons

\begin{tabular}{|c|c|c|c|c|}
\hline & & Persuasion & Consensus & Effect size Cohen's $d$ \\
\hline \multicolumn{5}{|l|}{ Repeated } \\
\hline Argumentative & Claim & $86.2(13.4)$ & $69.0(19.2)$ & 1.039 \\
\hline Structures (\%) & Claim data & $35.2(19.7)$ & $24.4(18.0)$ & 0.57 \\
\hline \multicolumn{5}{|l|}{ Different ideas in } \\
\hline the argumentative & Claim & $32.6(17.8)$ & $55.3(17.6)$ & 1.28 \\
\hline Structure (\%) & Claim data & $78.6(12.7)$ & $85.3(11.4)$ & 0.55 \\
\hline
\end{tabular}


1.039]. For the claim data argumentative structure, the mean for the persuasion group was $35.2(\mathrm{SD}=19.7)$, whereas the mean for the consensus group was 24.3 $(S D=18.0)$. Again, the $t$-test for comparing the means for the two conditions showed that the persuasion group made more repetitions of claim data than the consensus group $[t(63)=2.4 ; p=0.002$, effect size Cohen's $d=0.57]$. (See Table 2 for the distribution of means, standard deviations and effect sizes.)

\section{Rate of Diversity of Ideas: Different Ideas in the Argumentative Repetitions}

The second parameter for measuring the dependent variable is the number of different ideas contained in the two argumentative structures analysed (claim and claim data). For the claim structure, the mean percentage of different ideas in the persuasion condition was $32.6(\mathrm{SD}=17.8)$, and in the consensus condition it was 55.3 $(\mathrm{SD}=17.6)$ (see Table 2). The $t$-test used to compare the mean yielded significant differences. Specifically, the students' claims in the consensus group contained more ideas than did the claims of the students in the persuasion group $[t(63)=$ $-5.16 ; p=0.001$, effect size Cohen's $d=1.28$ ]. Similarly, for the claim data structure, the mean percentage of different ideas in the persuasion condition was 78.6 $(\mathrm{SD}=12.7)$, whereas in the consensus structure it was $85.3(\mathrm{SD}=11.4)$. The $t$ test used to compare the two means again yielded significant differences. The claim data structures of the students in the consensus condition contained significantly more ideas than did the claim data structures for students in the persuasion group $[t(63)=-2.2 ; p=0.028$, effect size Cohen's $d=0.55]$. Remember that this parameter was computed to determine the difference between the rates of repetitions, that is, to distinguish between the students who repeated the same idea over and over again and the students who repeated the same argumentative structure but used different ideas. Our results show that the students in the persuasion group not only repeated more structures of the types claim and claim data but also repeated the same ideas. In contrast, the students in the consensus condition did not repeat the structures as much as the students in the persuasion group. When they did repeat them, they presented a greater diversity of ideas. Before we turn to some dialogues to qualitatively illustrate the previous data, we want to comment that although all parameters analysed were normally distributed, the standard deviations for the percentage of repeated claim data structures and the percentage of different ideas in the claim structure were a little high compared to their respective means (see Table 2). In the case of claim data repetitions, there were eight students in the consensus condition and three in the persuasive condition that did not repeat any of them. This zero contrasts with the number of students whose percentage of repetitions was over $50 \%$ (there were a total of 21,15 of which belonged to the persuasive condition). A similar pattern was found for the percentage of different ideas in the claim structure. These patterns help explain the high variability of the data although, as mentioned, all four distributions were normally distributed.

In order to illustrate the differences between conditions, we present excerpts of four dialogues which represent the typical kinds of exchanges observed in the two 
conditions. The first two excerpts, between Lorena and Isa, and between Mary and Gerard are taken from the persuasive task condition. The other two excerpts, between Alex and Paul, and between Anna and Mike are taken from the consensus task condition. They address dilemmas 1 and 3, respectively. As mentioned in the Method section, all dialogues lasted approximately $15 \mathrm{~min}$. To facilitate data analysis, each utterance has been numbered in each dialogue. In the first dialogue, we see that Isa thinks thermal energy ('Option $A$ ') is the better option, whereas Lorena advocates for nuclear energy ('Option $B$ '). Lorena prefers nuclear power plants because they do not contaminate the environment as much as fossil fuels and she repeats this argument four times in utterances 12, 14, 20 and 28. Also, in utterances 10, 16, 18, 24, 26 and 30, Lorena simply restates her position several times, and occasionally replies to Isa's requests for justification by saying that the $\mathrm{CO}_{2}$ released into the atmosphere has serious consequences for the environment due to the greenhouse effect. Each utterance is followed by a code used to capture its argument structure and unique content. For example, Lorena's first utterance, which is labelled L:C1, is a claim structure $(\mathrm{C})$ which is the first such structure she has produced in the dialogue (1).

10. Lorena: Well, I think it is better to install a nuclear power plant than a thermal station.

(L:C1)

11. Isa: But why? (uncoded)

12. Lorena: Because nuclear power stations contaminate less than thermal stations (L:CD1)

13. Isa: I think $A$ (thermal power) is better, and you? And you? (I:C1)

14. Lorena: No. I think that B (nuclear power) is better, nuclear power stations contaminate less than thermal stations. (L:CD1)

15. Isa: But in a nuclear power station there may be leaks and it may be very dangerous when there are leaks. (I:CD1)

16. Lorena: Then I do not know, but I won't change my opinion. (L:C1)

17. Isa: Come on! Then what do we do? (uncoded)

18. Lorena: I do not want a thermal power station (L:C1)

19. Isa: Well, I think $A$ (thermal power) is better because leaks are likely to happen and when there is one, it is very bad. (I:CD1)

20. Lorena: No - I think nuclear power stations are better because thermal stations contaminate more. (L:CD1)

21. Isa: $B u t \ldots$ (uncoded)

22. Lorena: None of what you say would happen (L:CD2)

23. Isa: But if there is only one leak, even only one, it is very likely! I know (thermal stations) produce climate change but a leak is a problem without a solution. There's no going back. (I:CDWR)

24. Lorena: No, look, a nuclear power station is better. (L:C1)

25. Isa: What are you saying? (uncoded)

26. Lorena: That a nuclear power station is better. (L:C1)

27. Isa: Why? Come on, tell me why? (uncoded)

28. Lorena: Because it contaminates less, yours contaminates more! (L:CD1)

29. Isa: Yours contaminates and it is very risky for leaks. I think $A$ (thermal) is much better. (I:CD1)

30. Lorena: I think B (nuclear power) is better (L:C1)

31. Isa: But why? (uncoded)

32. Lorena: I will repeat it to you! (uncoded) 
Although this excerpt is only a small part of Lorena and Isa's dialogue, the conversation continues in the same vein. Lorena repeats the same claim data structure once more and Isa keeps pressing her point about the risk of radiactive leaks and its effect on people's health. Isa eventually accepts Lorena's claim about the health risks of nuclear power stations, but maintains that the risk of the greenhouse effect is even greater in comparison. Lorena ignores the comparison and continues to repeat herself without developing her argument to dismiss Isa's opposing view.

The second excerpt is also from the persuasive condition, but in this case, the participants discuss installing a windmill farm to solve their local energy needs. As with the first excerpt, we observe short utterances, and the frequent repetition of claim and claim data structures with few ideas brought into discussion. For example, in utterances 15, 17 and 23 Mary proposes the idea of taking animals out of the area to protect them, and in utterances 20 and 24, Gerard poses the problem of putting the idea into practice. There are a considerable number of claims repeated, especially towards the end, when they need to restate their position in the debate. Mary's 19, 21, 27, 29, 31, 33 and Gerard's 26, 30, 32 and 34 illustrate this point.

10. Gerard: The only thing that matters is that in the area where they want to put the windmill farm there is a ramp to skate and I like it. Also I don't want the Government to destroy the ecosystem. (G:CDD1)

11. Mary: But what would be destroyed is not very important. (M:CD1)

12. Gerard: It is definitely very important. (G:CD2)

13. Mary: Nothing happens because a few trees get cut. (M:CD1)

14. Gerard: No, I don't want to get a windmill farm built. (G:C1)

15. Mary: If the windmill farm affects animals they can remove [the animals] from that area. (M:CD2)

16. Gerard: This is impossible. How would you take them away? (G:CD3)

17. Mary: Well, look, we hunt them with nets and we take the animals to another area. (M:CD2)

18. Gerard: Do not say nonsense! (G:uncoded)

19. Mary: Well, it is clear (M:C1)

20. Gerard: Animals can't be taken to another place so easily. (G:CD3)

21. Mary: Of course they can! (M:C1)

22: Gerard: How? (G:uncoded)

23: Mary: Quite simply, remove the animals. Those who protect the animals could come and take them. (M:CD2)

24. Gerard: No. They can't take the birds to another area. (G:CD3)

25. Mary: Why not? (M:uncoded)

26. Gerard: fust because. (G:C1)

27. Mary: I say that the windmill farm must be installed. Is that clear? (M:C1)

28. Gerard: Yes. (uncoded)

29. Mary: I defend option A (M:C1)

30. Gerard: No (G:C1)

31. Mary: Option $A$ and that's it. (M:C1)

32. Gerard: Option $B$ and that's it. (G:C1)

33. Mary: I will not change my mind. (M:C1)

34. Gerard: Neither will I, I still think that the windfarm should not be installed. (G:C1). 
The two measures used to compare the conditions are clearly observed in the previous excerpts. As we can see, the higher rate of repetitions and lower proportion of new ideas are manifested in a kind of disconnected discourse where little headway is made. The four students reiterate the same ideas over and over without adapting their arguments to address their partner's comments and questions. Surprisingly, at the end of the dialogue, Lorena, in the first excerpt, suddenly changes her opinion without explanation and without any attempt to explore her partner's arguments, while as mentioned, Mary and Gerard, towards the end, repeat their claim 5 and 4 times, respectively, ignoring each other's comments.

The previous excerpts show a common trend: short utterances, higher frequencies of claim and claim data, and higher occurrence of repetitions. In contrast, the two excerpts that follow, taken from the consensus condition, illustrate two trends that lead to fewer repetitions and richer semantics. One trend reflects more complex structures beyond the simple but common structures of claim and claim data, fact that makes repetitions less straightforward. This is illustrated in Alex and Paul's dialogue. The other trend is reflected by the high presence of simple structures such as claim and claim data, but containing a higher diversity of ideas. This is illustrated in Gerard and Mary's excerpt.

The first dialogue below is between Alex and Paul, two students in the consensus condition. Alex is in favour of a thermal power station and Paul supports installing a nuclear power plant. In the beginning of the excerpt, they each talk about the negative health consequences of their partner's choice. They each then acknowledge that the health consequences are bad and argue about which one is worse. Paul moves on to the issue of greenhouse gas emissions and Alex counters by arguing that radioactive waste is even more dangerous for the environment. They touch on the efficiency of each option and end up deciding to look for another option, since both of their options are flawed.

1. Alex: OK, but if you compare ... the nuclear power station can cause malformations and other health problems. (A:CD1)

2. Paul: But it's been shown that thermal power stations run by fossil fuels affect people's health. (P:CD1)

3. Alex: Ok, but cancers are more harmful. (A:CD2)

4. Paul: I know.., but (P:uncoded)

5. Alex: Also, the breathing illnesses that you mention are not general across all cases (A:CD3)

6. Paul: Yes, but I find that the most important thing is that nuclear power stations don't produce Greenhouse gases, only emit water steam and nothing else, that's it. So the emissions are only water. (P:CDW1)

7. Alex: I know, but the gases that are emitted in a thermal power station run by fossil fuels would only affect the Greenhouse effect and maybe a minor health problem but the nuclear power station implies more serious consequences (A:CDR1).

8. Paul: OK, I keep thinking that a nuclear power station is better because in the future we know that the sources of fossil fuel will be used up. That is, the fuel, carbon, and natural gas will be used up and then [the lack of] these raw materials will not allow us to create the central power stations that you defend. So, for this reason it's better that from now on we stop spending the sources of fossil fuel and we choose the option of nuclear energy. For me, nuclear energy is better. (P:CDW2) 
9. Alex: OK, but five thermal power stations contaminate as much as five nuclear power stations. And on top of that, if we add more nuclear power stations we need more money for their construction and maintenance, since you can't forget that radiactive waste has to be treated for centuries and that is very expensive. (A:CDW1)

10. Paul: Ok, what you just said is true. Maybe with the money that it costs to maintain five thermal power stations we could only build one nuclear power station. But remember that one nuclear power station gets a million times more energy daily than a power station that works on carbon combustion. Also, if five thermal power stations are built, this may cause an increase in $\mathrm{CO}_{2}$ emissions on our planet and climate change would get worse. This effect on cimate change could be harmful for lots of plants and animal species that could not adapt to the temperature increase. Many would disappear. Imagine that many plant species disappeared, who would make the photosynthesis to give us oxygen, who? You and your thermal power stations? (P:CDWR1)

11. Alex: I know this coud happen, but I don't think that so many plant species would die that we'd run out of oxygen! (A:CDR2)

12. Paul: Well, this is unknown, but without plants we would not be able to live, because if the plants die, how would we breathe? (P:CDW3)

13. Alex: Well, I don't think that all the plants would die. Look, the cactus for sure would resist the climate change. What I want to say is that many plant species would adapt to the new temperature increase on the planet. (A:CDW2)

14. Paul: Well, we don't now how many species will be able to adapt, maybe scientists know. (P:CD2)

15. Alex: Well, it is clear that the two kinds of power stations are negative and if we don't reach an agreement about which one is better, then we will have to find a solution. I think that an alternative to the installation of one or the other, is the installation of windmill farm. I think it's a good choice because the aerogenerators work with wind. And although it's true that we need a lot of windmills, the energy is renewable, they do not produce $\mathrm{CO}_{2}$, they do not pruduce watse, it is easy to obtain and it contributes to technological development. (A:CDWR1)

In this excerpt, we see that neither Alex nor Paul repeats any claim or any claim data structures, engaging instead in a semantically rich and interactive dialogue where several new ideas are introduced and discussed. In contrast to the previous excerpt, we see how Alex and Paul each build new arguments based on his partner's contributions, trying to contrast the options and defend his position. In general, they address their partner's message by re-elaborating what they say and adding new information. And, although they disagree with each other for most of the dialogue, they do not ignore one another or refuse to participate. At the end of the excerpt, Alex observes that both options are flawed and proposes an alternative energy source (windmill energy) that seems to overcome all the problems raised in the dialogue. Overall, we see two important features of consensus seeking in this dialogue. First, each partner is willing to consider opposing viewpoints and respond substantively, as we see in the string of counterarguments (utterances $1-7,8-10$ and finally in 11-15). Rather than repeating themselves, they elaborate their arguments by rebutting their partner (signalled by the phrase 'Ok, but...'). Second, because each partner is willing to abandon his position, he is willing to consider and explore the limitations of his argument, as illustrated in Alex's final proposal to choose windmill farms.

The last dialogue excerpt is by Anna and Mike discussing the benefits of installing a windmill farm to supply energy (Dilemma 3). In this dialogue we see the high use of 
claim and claim-data structures found in the persuasive condition, but also a higher diversity of concepts with infrequent repetition.

6. Anna: Yes ... but I'm for the nuclear power station, it would reduce the greenhouse effect and it would reduce the acid rain (A:CD1)

7. Mike: The disadvantage of nuclear power stations is that they produce $\mathrm{CO}_{2}$, no, no, no, sorry, it does not produce $\mathrm{CO}_{2}$ ! (M:CD1)

8. Anna: For this reason, a nuclear power station is better, because it does not contaminate (A:CD2)

9. Mike: No, because it also ... With nuclear energy, if there is a leak, it is very dangerous (M:CD2)

10. Anna: No! (A:C1)

11. Mike: Thermal power stations with fossil energy are better than nuclear stations, it is better. The installation of the nuclear power station produce radioactive waste (M:CD3)

12. Anna: Nuclear power stations generate more energy than thermal stations (A:CD3)

13. Mike: We already have seven nuclear power stations in Spain. We cannot build any more, we have 7 already. (M:CD4)

14. Anna: Seven is not enough (A:CD4)

15. Mike: Nuclear power stations do not make profit of the $\mathrm{CO}_{2}$ while thermal power stations do.

High speed neutrons are shot into the atomic nucleus. (M:CD5)

16. Anna: I do not understand what you are saying, but you are wrong. You are talking about nuclear power stations and you mention $\mathrm{CO}_{2}$. And $\mathrm{CO}_{2}$ has nothing to do with it. (A:CD5)

17. Mike: The disadvantages are that nuclear power stations last for centuries, ifyou want to stop it, you cannot and they must be very safe because if there is a leak .... (M:CD6)

18. Anna: But coal will disappear, and what will we do when we run out of it? (A:CD6)

19. Mike: We will use another type of energy. We do not agree at all, why don't we go for another type, for instance wind energy or sun energy? (M:C1)

20. Anna: I do not want wind energy, it is very expensive (A:CD7)

21. Mike: Then what about water energy (M:C2)

22. Anna: You mean hydraulic energy? What about when we run out of water? (A:CD8)

23. Mike: We'll never run out of water (M:CD7)

24. Anna: Yes, we can run out of water, look at the drought we are suffering from now (A:CD8)

25. Mike: So, we can get water from countries where there are no droughts (M:CD8)

26. Anna: But those countries where there is drought will not be able to produce energy (A:CD8).

Mike and Anna finish the dialogue reaching consensus on solar energy. We observe, as mentioned, that in spite of the simple structures used in the dialogue, in each one of them appear a new idea with only one claim data repeated by Anna(A:CD8) towards the end of the dialogue.

The two dialogues in the consensus condition show a lack of repetitions but for different reasons. The first pair (Paul and Alex) produces more complex structures in lieu of repetitions, while the second pair (Anna and Mike) produces a wide array of simple structures with a high number of different of ideas, in place of repetitions. In both cases though we observe that the diversity of ideas is higher in the consensus condition compared to the persuasive one, where the students defend a few ideas over and over through the dialogue.

\section{Discussion}

The results of this study support the hypothesis that task instructions are associated with the use of argument repetitions in dialogues. When two groups of students 
were presented with different argumentative prompts, the group prompted to convince their opponent (persuasion task) repeated more argumentative structures and generated fewer ideas, showing a semantically poorer discourse than the group prompted to reach agreement (consensus task). In contrast, the students in the consensus group showed fewer repetitions, and demonstrated a higher diversity of ideas. These results suggest that the goal to persuade prompted the young adolescents in our study to repeat a limited array of ideas over and over in an attempt to dismiss opposing views, signalling a departure from the kind of dialectical reasoning we would hope to foster in science classrooms.

These results are in concordance with those by Nussbaum (2005), which point to the persuasion goal as a more adversarial type of discourse, in which students, in their attempt to 'prove' a specific point of view, may explore the problem less deeply because the persuasion goal leads them to consider only ideas that support their own position. When persuasion is the goal of dialogue, individuals may dismiss counterarguments to convince others to adopt their conclusions (Felton et al., 2009). Furthermore, persuasion goals may polarize individuals' opinions by provoking confirmation bias in their thinking. As a result, argumentative dialogue might actually limit knowledge construction by making students resistant to examining and potentially revising their initial beliefs. In the persuasion condition, argument repetitions seem to serve as a kind of defensive move, where students repeat themselves rather than address legitimate critical questions and comments from peers.

Lynch, George, and Cooper (1997) add to this concept by noting the impact of persuasive argumentation on students' learning. They state that by arguing vigorously and even angrily,

students do not think about alternatives, or listen to each other, or determine how their position may affect others, or see complexities, or reconsider the position they began with, or even make new connections across a range of possible disagreement. (Lynch et al., 1997, p. 65)

Findings from our study support this claim, demonstrating that persuasive goals can compromise the quality of argumentative discourse by triggering strategies that interfere with the social construction of knowledge. These findings also help to explain the results reported in Felton et al. (2009), which show that although both groups of students demonstrated a significant amount of content learning over a control group, students' learning was significantly higher in the consensus group than in the persuasion group. The competitive discourse that emerged in the persuasion group produced a context in which a limited range of ideas were exchanged, and in which ideas were often dismissed or ignored. Thus, results of this study support the hypothesis that students' task goals while arguing mediate the effects of argumentative discourse on learning by affecting the rate of repetitions and the conceptual richness of dialogue.

Despite our findings, we do not wish to suggest that argumentative discourse must lead to consensus to be effective, or that teachers should encourage students to blindly seek agreement in their dialogues. Instead, we suggest that the way in which an 
argumentative task is framed will elicit different kinds of discourse strategies from young adolescents, and that these differences may impact learning. Persuasive goals are not inherently antithetical to deliberative discourse. In fact, Walton (1992) points out that persuasion is one of the eight steps in reason-based deliberative discourse aimed at consensus. However, in deliberative discourse, persuasive dialogue is situated in a broader process that involves elaborating alternatives and weighing their relative merits before committing to one side or another. Our findings point to the importance of clarifying task goals with students before they engage in argumentative discourse. By the time they arrive to school, most young adolescents have far more experience in dispute than they do with deliberation. When instructed to persuade or convince in school, student may call up discourse goals and strategies more akin to dispute than deliberation. To foster alternative-based reasoning among adolescents, we must help students understand that the goal of argumentative discourse is to arrive at conclusions, rather than defend them tooth and nail. Ultimately, for argumentative discourse to have a positive effect on learning, individuals must seek to respond substantively to questions and challenges of their conversational partners, and they must be open to re-evaluating their claims (von Aufschnaiter, Erduran, Osborne, \& Simon, 2008). Without this attempt to engage in an authentic exchange of views, they cannot experience the benefits of being prompted to elaborate upon their arguments or the benefits of weighing conclusions against their alternatives (Kuhn, 2005). In short, they have to be open to critically examining their own and others' arguments in support of conclusions. We believe these findings have several important implications for educators. First, while one might be tempted to assume that argument repetition among adolescents is simply the result of their limited content knowledge, our results suggest that other factors may be at work. As the students in the consensus group demonstrated, under the right conditions, young adolescents are able to cite a wide variety of ideas and structures in support of their conclusions. Repetition, or the paucity of ideas exchanged in a conversation, may say more about students' task goals while arguing than the breadth of their content knowledge. Moreover, task goals may also have a consequential effect on their content knowledge. A second, equally important finding is that the way in which teachers frame an argument task can have a significant impact on student learning outcomes. When arguing to convince, students are exposed to a limited range of alternative perspectives and show lower recall of this opposing information at a later date. While setting students to the task of persuading peers may seem engaging and fun, it may lead students to pursue discourse goals that are at odds with learning.

To interpret the amount of repetition and learning, we see a parallel between the argumentation goals we have studied here and the types of classroom talk defined by Mercer (2000). Mercer (2000) looks at classroom conversational activities to analyse their relationship with the co-construction of knowledge. He emphasizes that not all types of classroom conversation have the same educational value. Mercer (2000) distinguishes three types of classroom talk: disputative, cumulative and exploratory. In cumulative talk, a non-critical, non-competitive and constructive relation is established where the differences between the partners are minimized. 
In contrast, in the disputative talk, conversational partners are treated as a threat to our interests; the partners try to keep their identities separate to protect their individuality. Finally, Mercer defines exploratory talk as dialogue that explicitly deals with differences as a common topic to be explored, accompanied by a reasoned assessment to facilitate resolution. Exploratory talk uses explicit reasons, criticisms and assessments and the participants do not worry about protecting their interests, keep their individualities separate and endeavour to reach a common understanding. Mercer's main point is that these different types of classroom talk mediate learning differently. Mercer's (2000) distinction between exploratory talk on the one hand and cumulative and disputative on the other fits into our two types of discourse. Our students in the persuasive condition showed a discourse similar to that described by Mercer in the cumulative or the disputative talks, whereas the description he makes of the exploratory talk clearly matches with the discourse of the students in the consensus condition.

Similar to Mercer's (2000) idea of the varying educational value of classroom discussion, not all argumentative dialogues promote learning equally. When debate activities are proposed to students in the classroom, careful attention needs to be paid to the specific instructions given to them. We have seen how different prompts generate different types of dialogue with different argumentation strategies that lead to different uses of argumentation and result in different amounts of learning. Argumentative tasks have been proven to foster students' science learning, but as our findings show, students' argumentative tasks goals may not always be what we think they are. Teachers should not only avoid presenting argumentative tasks whose goal is to simply 'persuade a partner', they also should avoid proposing argumentative tasks without making the goals of discourse explicit. Argumentation has the potential to promote science learning, but only when students understand the collaborative power of dialogue to examine and revise their beliefs in light of their alternatives.

This study presents two limitations. The first one refers to the incomplete picture of the discourse that occurred in each of the two conditions. We have inferred from the task instructions that students engage in either persuasion and consensus seeking in this study, but without a comprehensive analysis of the students' utterances in the dialogues, we cannot say for certain what kinds of argumentative discourse occurred in each condition. Ultimately, a more complete analysis of discourse features will be necessary to argue that specific kinds of discourse are associated with learning outcomes. The second limitation lies in the fact that the analysis we made takes as the unit of analysis the individual. We are working on an analysis that takes as a unit of analysis the dyad and the interactions between the partners. Felton and Kuhn (2001), for instance, have created an analytic scheme that can be used to examine the function of utterances in argumentative dialogue. They have used this coding scheme to analyse the impact of a variety of conditions and interventions on both the process and outcomes of argumentative discourse (Felton, 2004; Felton \& Kuhn, 2001; Kuhn \& Crowell, 2011; Kuhn \& Udell, 2003). At present, we have limited ourselves here to the conclusion that task instructions were associated discourse features and help interpret the findings on content learning. However, a next step will be to analyse these data to look for the characteristic features of 
dispute and deliberation in students' dialogues and draw more precise conclusions about the impact of either on science learning.

\section{Acknowledgements}

The present work was made due to the funding to the first author by the Generalitat de Catalunya (Spain) and by the European Social Funds (EDU/3600/2006) and to the second and third authors by the Ministerio de Educación y Ciencia (Spain) with project numbers EDU2010-21995-C02-02 and SAB2010-0124 respectively.

\section{Notes}

1. The total sample consisted of 101 students. Sixty-five students were assigned to either the persuasion condition or to the consensus condition, and 35 students were assigned to a third condition that was not asked to argue to test the effect of argumentation in learning (Felton et al., 2009). Because the non-argumentative group is irrelevant for the purposes of the present study, this paper only takes into consideration the 65 students who were assigned to either of the two argumentative conditions.

2. Names are pseudonyms.

\section{References}

von Aufschnaiter, C., Erduran, S., Osborne, J., \& Simon, S. (2008). Arguing to learn and learning to argue: Case studies of how students' argumentation relates to their scientific knowledge. Fournal of Research in Scientific Thinking, 45, 101-131.

Berland, L.K., \& Reiser, B. (2009). Making sense of argumentation and explanation. Science Education, 93(1), 26-55.

Bricker, L., \& Bell, P. (2008). Conceptualizations of argumentation from science studies and the learning sciences and their implications for the practices of science education. Science Education, 92, 473-498.

Cacioppo, J.T., \& Petty, R.E. (1989). Effects of message repetition on argument processing, recall and persuasion. Basic and Applied Social Psychology, 10, 3-12.

Chin, C., \& Osborne, J. (2010). Students' questions and discursive interaction: Their impact on argumentation during collaborative group discussions in science. Fournal of Research in Science Education, 47, 883-908.

Claypool, H.M., Mackie, D.M., Garcia-Marques, T., McIntosh, A., \& Udall, A. (2004). The effects of personal relevance and repetition on persuasive processing. Social Cognition, 22, 310-335.

Driver, R., Newton, P., \& Osborne, J. (2000). Establishing the norms of scientific argumentation in the classroom. Science Education, 84, 287-312.

Duschl, R.A. (2008). Science education in three-part harmony: Balancing conceptual, epistemic and social learning goals. Review of Research in Education, 32, 268-291.

Duschl, R.A., \& Osborne, J. (2002). Supporting and promoting argumentation discourse. Studies in Science Education, 38, 39-72.

Duschl, R.A., Schweingruber, H.A., \& Shouse, A.W. (2007). Taking science to school: Learning and teaching science in grades K-8. Washington, DC: National Academy Press. Retrieved from http://www.nap.edu

Erduran, S., Simon, S., \& Osborne, J. (2004). TAPping into argumentation: Developments in the application of Toulmin's Argument Pattern for studying science discourse. Science Education, 88, 915-933. 
Felton, M. (2004). The development of discourse strategy in adolescent argumentation. Cognitive Development, 19, 39-58.

Felton, M., Garcia-Mila, M., \& Gilabert, S. (2009). Deliberation versus dispute: The impact of argumentative discourse goals on learning and reasoning in the science classroom. Informal Logic, 29, 417-446.

Felton, M., \& Kuhn, D. (2001). The development of argumentive discourse skill. Discourse Processes, $32,135-153$.

Golder, C. (1996). Le développement des discours argumentatifs [The development of argumentative discourse]. Lausanne: Delachaux et Niestlé.

Goodwin, M., \& Goodwin, C. (1987). Children's arguing. In S. Philips, S. Steele, \& C. Tanz (Eds.), Language, gender, and sex in comparative perspective (pp. 200-248). Cambridge: Cambridge University Press.

Jimenez-Aleixandre, M.P., \& Erduran, S. (2008). Argumentation in science education: An overview. In S. Erduran \& M.P. Jimenez-Aleixandre (Eds.), Argumentation in science education. Perspectives from classroom-based research (pp. 3-29). New York: Springer.

Johnstone, B. (1987). An introduction. Text: An Interdisciplinary fournal for the Study of Discourse, 7(3), 205-214.

Johnstone, B. (1996). The linguistic individual: Self-expression in language and linguistics. New York: Oxford University Press.

Kelly, G.J., \& Chen, C. (1999). The sound of music: Constructing science as sociocultural practices through oral and written discourse. Fournal of Research in Science Teaching, 36, 883-915.

Kelly, G.J., \& Crawford, T. (1997). An ethnographic investigation of the discourse processes of school science. Science Education, 81, 533-559.

Kelly, J.G., \& Takao, A. (2002). Epistemic levels in argument: An analysis of university oceanography students' use of evidence in writing. Science Education, 86, 314-342.

Kim, H., \& Song, J. (2006). The features of peer argumentation in middle school students' scientific inquiry. Research in Science Education, 36, 211-233.

Kroll, B.M. (2005). Arguing differently. Pedagogy, 5, 37-60.

Kuhn, D. (2005). Education for thinking. London: Harvard University Press.

Kuhn, D. (2010). Teaching and learning science as argument. Science Education, 94, 810-824.

Kuhn, D., \& Crowell, A. (2011). Dialogic argumentation as a vehicle for developing young adolescents' thinking. Psychological Science, 22(4), 545-552.

Kuhn, D., \& Udell, W. (2003). The development of argument skills. Child Development, 74(5), $1245-1260$.

Lehrer, R., Schauble, L., \& Petrosino, A. (2001). Reconsidering the role of experiment in science education. In K. Crowley, C. Schunn, \& T. Okada (Eds.), Designing for science: Implications from everyday, classroom, and professional settings (pp. 251-278). Mahwah, NJ: Lawrence Erlbaum Associates.

Lemke, J. (2002). Enseñar todos los lenguajes de la ciencia: Palabras, símbolos, imágenes y acciones [Teach all languages of science: Words, symbols, images and actions]. In M. Benlloch (Ed.), La educación en ciencias. Ideas para mejorar su práctica [Education in science: Ideas to improve its practice] (pp. 159-186). Barcelona: Paidós.

Lynch, D., George, D., \& Cooper, M. (1997). Moments of argument: Inquiry and confrontational cooperation. College Composition and Cooperation, 48, 61-85.

Makau, J.M., \& Marty, D.L. (2001). Cooperative argumentation: A model for deliberative community. Prospect Heights, IL: Waveland Press.

Maloney, J., \& Simon, S. (2006). Mapping children's discussions of evidence in science to assess collaboration and argumentation. International fournal of Science Education, 28, 1817-1841.

Mercer, N. (2000). Words and minds: How we use language to think together. London: Routledge.

Mercer, N., Dawes, L., \& Wegerif, R. (2004). Reasoning as a scientist: Ways of helping children to use language to learn science. British Educational Research fournal, 30, 359-377. 
Metsämäki, M. (2009). Influencing through language-university students' argumentation strategies. AFinLA-e: Applied Linguistics Studies, 1, 61-76.

Nussbaum, E.M. (2005). The effect of goal instructions and need for cognition on interactive argumentation. Contemporary Educational Psychology, 30, 286-313.

Nussbaum, E.M. (2008). Using argumentation vee diagrams (AVDs) for promoting argumentcounterargument integration in reflective writing. Fournal of Educational Psychology, 100, $549-565$.

Nussbaum, E.M. (2011). Argumentation, dialogue theory, and probability modelling: alternative frameworks for argumentation research in education. Educational Psychologist, 46, 84-106.

Nussbaum, E.M., \& Kardash, C.M. (2005). The effects of goal instructions and text on the generation of counterarguments during writing. Fournal of Educational Psychology, 97, 157-169.

Osborne, J., Erduran, S., \& Simon, S. (2004). Enhancing the quality of argumentation in school science. Fournal of Research in Science Teaching, 41, 994-1020.

Osborne, J., \& Patterson, A. (2011). Scientific argument and explanation: A necessary distinction? Science Education, 95, 627-638.

Scott, S. (2002). Linguistic feature variation within disagreements: An empirical investigation. Text: An Interdisciplinary fournal for the Study of Discourse, 22(2), 301-328.

Simon, S., Erduran, S., \& Osborne, J. (2006). Learning to teach argumentation: Research and development in the science classroom. International fournal of Science Education, 28, 235-260.

Syh-Jong, J. (2007). A study of students' construction of science knowledge: Talk and writing in a collaborative group. Educational Researcher, 49, 65-81.

Vygotsky, L.S. (1978). Mind and society. Cambridge, MA: Harvard University Press.

Walton, D.N. (1992). Plausible argument in everyday conversation. Albany, NY: State University of New York Press.

Walton, D.N. (1997). What is propaganda, and what exactly is wrong with it? Public Affairs Quarterly, 11, 383-413.

Zohar, A., \& Nemet, F. (2002). Fostering students' knowledge and argumentation skills through dilemmas in human genetics. Fournal of Research in Science Teaching, 39, 35-62. 
Appendix 1. Rubrics for Coding the Argumentative Structures

\begin{tabular}{|c|c|c|}
\hline Type & Definition & Example \\
\hline Claim & Only the thesis & I want a nuclear power station. I do not want a thermal station \\
\hline Claim data $(\mathrm{CD})$ & The thesis is followed by data that supports it & $\begin{array}{l}\text { I want the nuclear power station because it does not produce } \mathrm{CO}_{2} \text {, } \\
\text { and it can also produce more electrical energy }\end{array}$ \\
\hline Claim backing (CB) & $\begin{array}{l}\text { The thesis is followed by one or more theoretical or historical } \\
\text { statements that support it }\end{array}$ & $\begin{array}{l}\text { I want the thermal power station because there are still people who are } \\
\text { sick due to the Chernobyl accident }\end{array}$ \\
\hline Claim rebuttal (CR) & $\begin{array}{l}\text { The thesis is followed by a comment that admits limitations or } \\
\text { by one or more features that support the opponent's thesis }\end{array}$ & $\begin{array}{l}\text { I prefer the nuclear power station. Although if there were a leak, the } \\
\text { effects would last for many years }\end{array}$ \\
\hline $\begin{array}{l}\text { Claim data warrant } \\
\text { (CDW) }\end{array}$ & $\begin{array}{l}\text { The thesis is followed by one or more statements of data and by } \\
\text { further elaborations to help justify the data }\end{array}$ & $\begin{array}{l}\text { I support the nuclear power station because it does not produce } \mathrm{CO}_{2} \text {; } \\
\text { thus, it will neither increase the greenhouse effect nor produce acid } \\
\text { rain }\end{array}$ \\
\hline $\begin{array}{l}\text { Claim data backing } \\
\text { (CDB) }\end{array}$ & $\begin{array}{l}\text { The thesis is followed by one or more statements of data and is } \\
\text { followed by a theoretical or historical statement that justifies } \\
\text { them }\end{array}$ & $\begin{array}{l}\text { I support the nuclear power station because it will not increase the } \\
\text { greenhouse effect and it will not violate the Kyoto Agreement to reduce } \\
\mathrm{CO}_{2} \text { contamination }\end{array}$ \\
\hline $\begin{array}{l}\text { Claim data rebuttal } \\
\text { (CDR) }\end{array}$ & $\begin{array}{l}\text { The thesis is followed by data and by limitations and/or features } \\
\text { that support the opponent's claim }\end{array}$ & $\begin{array}{l}\text { Ilike the thermal energy project because there is no risk of radioactive } \\
\text { leaks, although I admit that nuclear energy does not produce } \mathrm{CO}_{2}\end{array}$ \\
\hline $\begin{array}{l}\text { Claim data warrant } \\
\text { backing (CDWB) }\end{array}$ & $\begin{array}{l}\text { The thesis is followed by data containing statements that } \\
\text { support it and by theoretical or historical statements that } \\
\text { support it }\end{array}$ & $\begin{array}{l}\text { I support the thermal energy project because nuclear power stations } \\
\text { can cause radioactive leaks, and this can cause cancer problems, as in } \\
\text { Chernobyl }\end{array}$ \\
\hline $\begin{array}{l}\text { Claim data warrant } \\
\text { rebuttal (CDWR) }\end{array}$ & $\begin{array}{l}\text { The thesis is followed by data that support it, followed by } \\
\text { statements that support the data, and by limitations of the } \\
\text { claim that refer to positive aspects of the partner's claim }\end{array}$ & $\begin{array}{l}\text { I propose the nuclear power station because it does not generate the } \\
\text { greenhouse effect, which would be very harmful for the adaptation of } \\
\text { certain species, although it is true that it could cause nuclear accidents }\end{array}$ \\
\hline $\begin{array}{l}\text { Claim data backing } \\
\text { rebuttal (CDBR) }\end{array}$ & $\begin{array}{l}\text { The thesis is followed by data, by theoretical or historical } \\
\text { statements that support it, and by limitations of the claim that } \\
\text { refer to positive aspects of the partner's claim }\end{array}$ & $\begin{array}{l}\text { I propose the thermal station because it does not generate radioactive } \\
\text { waste and because there could be nuclear accidents such as the one in } \\
\text { Chernobyl. Although I admit that the nuclear station would decrease } \\
\text { climate change }\end{array}$ \\
\hline $\begin{array}{l}\text { Claim data warrant } \\
\text { backing rebuttal } \\
\text { (CDWBR) }\end{array}$ & $\begin{array}{l}\text { The thesis is followed by data, by statements that support it, by } \\
\text { theoretical or historical statements that also support it, and by } \\
\text { limitations of the claim that refer to positive aspects of the } \\
\text { partner's claim }\end{array}$ & $\begin{array}{l}\text { I propose the thermal station because, although it generates high } \\
\text { amounts of } \mathrm{CO}_{2} \text {, we can prevent nuclear accidents. These could be } \\
\text { very harmful for the species in the area, as was the accident in } \\
\text { Chernobyl }\end{array}$ \\
\hline
\end{tabular}

